\title{
COMUNICAÇÃO EMPRESARIAL SEM PODER
}

\author{
César Augusto Sampaio \\ Universidade do Oeste Paulista - UNOESTE, Curso de. Graduado em Publicidade e Propaganda e com especialização \\ em Gestão de Marketing e Comunicação, Presidente Prudente, SP. E-mail: caugusto67@hotmail.com
}

\section{RESUMO}

O objetivo desse artigo é apresentar um estudo sobre a comunicação empresarial do ponto de vista interno, Tendo como método científico a documentação indireta através de pesquisas bibliográficas e documentais, constatou-se um subaproveitamento da comunicação empresarial. No âmbito da comunicação interna, é preciso estar atento à desagregação das relações interpessoais e grupais, que costumam causar uma intricada rede de poder revestida pela retenção de informações, pelos boatos, pela formação de feudos, pelas disputas hierárquicas, além das delações difamatórias entre funcionários.

Palavras-chave: Comunicação empresarial, Público interno, Poder.

\section{COMMUNICATION BUSINESS WITHOUT POWER}

\begin{abstract}
The objective of this paper is to present a study on the business communication from the internal point of view. With the scientific method through the indirect documentation of bibliographic and documentary research, found a underutilization of business communication. In the context of internal communication, we must be alert to the breakdown of interpersonal and group relations, which tend to cause an intricate network of power covered by the withholding of information by the rumors, the formation of fiefdoms, the hierarchical disputes, in addition to slanderous denunciations among employees.
\end{abstract}

Keywords: Business Communication, Public Internal, Power. 


\section{INTRODUÇÃO}

Com a crescente comoditização de produtos e serviços, aumentou a concorrência de mercado e os clientes ficaram cada vez mais exigentes. Vive-se, hoje, uma outra realidade, na qual os compradores não se importam apenas com os produtos da empresa, mas também com a imagem dela e com o quê ela defende, segundo Kotler, Kartajaya e Setiawan (2010).

É nesse cenário que a comunicação empresarial passa ser valorizada junto aos seus diversos públicos, como forma estratégica de aproximá-los, conquistá-los e fidelizá-los à missão, à visão e aos valores da corporação.

A comunicação empresarial é uma verdadeira guerra com muitas frentes de batalha: a frente de batalha voltada para mostrar que a empresa tem uma relação de respeito com a natureza, visando sobretudo a sua preservação (se você quiser, pode chamar frente de batalha ecológica); a frente de batalha para manter e conquistar novos consumidores; a frente de batalha da comunicação interna dirigida para os imensos exércitos de trabalhadores engravatados e de uniformes que constituem os recursos humanos das empresas modernas; a frente de batalha das complicadas relações das empresas com os governos e os políticos, ou seja, o lobby empresarial. E a grande frente de batalha da propaganda e da promoção de produtos (NASSAR; FIGUEIREDO, 1997, p. 20).

Uma boa percepção da corporação dependerá de uma boa comunicação integrada com todos esses stakeholders. Entretanto, tal fato ainda não está evidente no cotidiano das corporações, porque "elas continuam planejando sua interação com esses públicos como se eles pudessem ser reduzidos a um perfil único, a um pretenso perfil padrão" (BUENO, 2011, p. 124).

Para o autor, a maioria das empresas persiste em usar um veículo ou canal único para se relacionar com seus públicos de interesse, acreditando apenas em uma linguagem ou um discurso e em um formato, como se isso pudesse atender a uma gama diversificada de demandas e expectativas.

Prova disso está na constatação de que "a comunicação organizacional é comumente entendida por meio de uma forma: a comunicação social [...] é necessário abrir a visão sobre outras formas [...]" (TORQUATO, 2008, p. 34).

Sendo assim, esse artigo apresentará as outras componentes da comunicação empresarial, com ênfase no âmbito da sua comunicação interna. Espera-se, com isso, ampliar o conhecimento sobre esse tema e contribuir com subsídios relevantes para pesquisadores da área, estudantes e profissionais de mercado, haja vista que a intenção é abordar o uso da comunicação empresarial a serviço do desempenho e da produtividade. 


\section{METODOLOGIA}

O método de pesquisa utilizado foi o de documentação indireta através de referências bibliográficas e documentais. As primeiras serviram como reforço para uma melhor análise e manipulação das informações. Segundo Marconi e Lakatos (2003), o levantamento bibliográfico não só proporciona formas de se definir e resolver problemas já conhecidos, mas também garante maneiras de se explorar novas áreas onde eles ainda carecem de suficiente cristalização.

Quer dizer, não se trata apenas de uma mera repetição do que já foi dito ou escrito antes sobre certo assunto, mas, sim, de uma pesquisa que favorece o exame de um tema sob novo enfoque de abordagem, chegando a conclusões inovadoras.

Já as pesquisas documentais se pautam na coleta de dados feita em diversos documentos denominados de fontes primárias. O que possibilita colher informações prévias sobre o campo de interesse e, por conseguinte, uma melhor compreensão do objeto de estudo, afirmam Marconi e Lakatos (2003).

\section{RESULTADOS OBTIDOS DO ESTUDO DA COMUNICAÇÃO EMPRESARIAL}

Percebe-se, hoje, que há um subaproveitamento do potencial da comunicação empresarial, devido até mesmo ao desconhecimento e funcionamento de cada uma de suas partes. Estas são compostas pelo sistema de informação, comunicação social, comunicação administrativa e comunicação cultural.

A área de sistema de informação se responsabiliza pelo banco de dados, onde estão armazenadas diversas informações de interesse das corporações. Isto é, estatísticas, resultados de pesquisa, resenhas informativas, documentos variados, relatórios de medidas políticas, normas, estratégias mercadológicas e governamentais de níveis macro ambiental, entre outros.

Já a modalidade da comunicação social atende tanto ao público interno, quanto também ao público externo. Com este último, o objetivo é trabalhar o posicionamento e a imagem institucional da organização, além de gerar demanda para seus produtos e serviços. Em relação ao primeiro, a prioridade é manter um clima agradável que garanta um espírito de equipe em prol do cumprimento das metas e valores da empresa.

No que se refere à comunicação administrativa, ela é uma das maiores causadoras de ruídos que prejudicam as operações. A sua característica é a formalidade dos atos comunicacionais entre a cúpula diretiva e seus funcionários. Trata-se das normas, instruções, memorandos, regulamentos, portarias, avisos, entre outros, tendo em vista ordenar, atualizar e orientar as atividades funcionais. Muitas vezes, essas informações não chegam até determinado 
funcionário, estacionam-se no meio, seja por problemas gerencias, seja pelo acúmulo administrativo ou mesmo pela quantidade excessiva de canais de comunicação, de acordo com Torquato (2008).

Estudos mostram que as pessoas ainda não entendem como fazer para cumprir suas tarefas rotineiras de trabalho. Há uma falta de clareza na comunicação dos executivos, principalmente dos presidentes e diretores.

Como esperar melhor desempenho dos funcionários, quando $60 \%$ deles sequer compreendem quais são suas metas? É o que demonstrou pesquisa realizada pelo grupo DMRH, consultoria de recursos humanos de São Paulo, publicada na revista Você S.A, em 2009, (METHODUS, 2013).

Já no tocante à comunicação cultural, essa modalidade retrata o "clima" reinante dentro das organizações oriundo de um conjunto de características psicossociais que permeiam as relações entre seus integrantes.

Não é costume estudar e nem trabalhar operacionalmente a comunicação cultural (TORQUATO, 2008). Mesmo porque a sua implementação depende de uma decisão firme baseada na transparência, diálogo e contato direto com situações embaraçosas, difíceis de lidar, que serão discutidas a seguir.

\section{DISCUSSÃO}

Cabe a comunicação interna converter os funcionários em artífices construtores da imagem corporativa, visto que "uma empresa só conseguirá crescer junto ao seu mercado, quando seu público interno entender que, sempre, o processo de conquista e manutenção do cliente tem início e se sustenta internamente" (MARCHESI, 2005, p. 48).

E a comunicação administrativa exerce grande influência nesse processo. Nela, são frequentes os ruídos associados à má interpretação das informações, sobretudo porque nos baixos escalões costuma predominar vasta heterogeneidade sócio-cultural e maior dispersão de seus públicos.

Nesse caso, o mais prudente seria fazer uma transmissão em duas etapas. Ou seja, primeiramente a mensagem deveria ser passada ao líder de grupo, que a receberia e a interpretaria para, em seguida, ser repassada ao restante do público, orienta Torquato (1986). Embora isso facilite a assimilação da mensagem, muitas das dissonâncias e embaraços de interpretação seriam menores, se a comunicação descendente (ou comunicação administrativa) priorizasse uma dosagem mais concentrada de informação em seus conteúdos. Certamente 
haveria maior interesse dos colaboradores em praticar o que se determina (REZIN, 2010, apud REGGIERO, 2002).

Além disso, é preciso estar atento também à comunicação ascendente (das bases para os níveis hierárquicos superiores). Seus assuntos geralmente são pautados por conteúdos funcionais e operacionais, tratando de boletins com resultados de tarefas, opiniões, críticas, elogios, etc., obtidos através de reuniões, caixas de sugestões, pesquisas de climas organizacionais, entre outros.

Acontece que muitas das respostas fornecidas a tais mecanismos de coleta de informações costumam informar apenas o que consideram que os seus superiores desejam ouvir (PIMENTA, 2009).

Há de se lembrar também que grande parte das mensagens emitidas pelo público interno circula por vias informais, escapando do controle das corporações. Constata-se, por exemplo, que somente de $10 \%$ a $20 \%$ delas fluem pelo sistema ascendente, segundo Silva, Nascimento e Nogueira (2007).

As vias informais correspondem aos fluxos laterais em que as mensagens circulam no mesmo nível hierárquico de departamentos, seções, serviços, etc. Através delas, há mais espontaneidade com maior liberdade de expressão. Essas características agregam as pessoas e, se forem bem coordenadas estrategicamente, contribuem para fortalecer o compromisso do público interno com as metas e propósitos da organização.

Entretanto, verdadeiros focos de tensão costumam ser causados pelos fluxos laterais. Até mesmo porque a troca de mensagens internas é feita majoritariamente através dos fluxos descendentes, cuja falta de planejamento ocasiona um acúmulo de informações em suas vias comunicacionais, bloqueando a retroalimentação ou o feedback, argumenta Torquato (1986).

A partir daí, surgem os boatos sobre vários assuntos que repercutem negativamente na imagem da empresa, principalmente em momentos de crise. Essa é uma situação que deixa o ambiente à deriva, onde a visão coletiva perde espaço para interesses egotistas, os quais se prevalecem pela ardileza de certos procedimentos como o da retenção de informações.

Já se tornou costume estas serem repassadas só em momentos oportunos, quando houver favorecimento ou prestígio aos seus detentores. Isso ocorre frequentemente com gerentes e chefias intermediárias.

Esse modo de agir leva a uma sequência de pequenos episódios que vão se avolumando. A informação não chega até seu destinatário, e este fica sem noção clara de como exercer 
corretamente suas funções, logo perde a motivação e ganha o descontentamento que, certamente, encontrará abrigo no poder dos feudos.

Estes, por sua vez, são as famosas "panelinhas" ou redutos criados à revelia da empresa. Trata-se de pessoas que se sentem contrariadas em seus interesses. Na visão de Persona (2010), os feudos se constituem no maior problema que dificulta o trabalho da comunicação interna nas empresas.

Os feudos acabam gerando sentimentos nocivos, principalmente aqueles oriundos dos poderes da delação e das hierarquias que também afetam o rendimento das rotinas de trabalho. É o caso da inveja direcionada àqueles profissionais em ascensão no cenário organizacional, que pelos seus próprios méritos começam a angariar mais respeito e fama. Ao se destacarem, eles também se tornam alvo de delações infundadas e difamatórias, cuja finalidade é solapar o sucesso deles dentro da empresa.

O fato é que a força dessas delações não só contamina toda a rede informal com diversos comentários maledicentes, mas ainda acaba prejudicando o crescimento desses profissionais em evidência, afirma Torquato (1998).

E isso certamente vai acarretar incontáveis danos à empresa, afetar o equilíbrio intergrupal, causar atribulações entre setores e departamentos, desviando o foco da produção. Detectar esses transtornos exige um constante monitoramento do clima organizacional, tendo em mente que não basta só a influência remunerativa, as regras estabelecidas pelas normas e, muito menos, as ameaças da força coercitiva para conseguir a cooperação dos trabalhadores.

Ao invés disso, o mais aconselhável é convencer e persuadir, despertando sentimentos e expectativas que induzam a comportamentos e atitudes capazes de gerar participação e solidariedade. Enfim, humanizar e sensibilizar pela força da comunicação.

\section{CONCLUSÃO}

A elaboração desse artigo teve a finalidade de mostrar a comunicação empresarial do ponto de vista interno. Constatou-se um subaproveitamento do seu potencial. Ainda é comum, por exemplo, ela ser confundida com a comunicação social.

Além disso, estudos mostraram que as pessoas ainda não entendem como fazer para cumprir suas tarefas rotineiras de trabalho.

Há uma falta de clareza na comunicação dos executivos, principalmente dos presidentes e diretores. Ademais, não há uma preocupação em entender o "clima" organizacional ao redor de gerentes, diretores e demais funcionários, isto é, as relações psicossociais. 
Portanto, cabe a comunicação interna exercer a sua força persuasiva no sentido de unificar, integrar e harmonizar as relações de trabalho, proporcionando climas mais cordiais, solidários e humanizados.

\section{REFERÊNCIAS}

BUENO, Wilson da Costa. As transgressões conceituais em Comunicação Organizacional. Revista Organicom, 2011. Disponível em: <revistaorganicom.org.br> Acesso em: 9 Janeiro 2015.

KOTLER, Philip; KARTAJAYA, Hermawan; SETIAWAN, Iwan. Marketing 3.0: As forças que estão definindo o novo marketing centrado no ser humano. Tradução: Ana Beatriz Rodrigues. 9. reimp. Rio de Janeiro: Elsevier, 2010.

MARCHESI, Amauri. Comunicação interna: A força das empresas. Comunicação interna, fator humano como diferencial competitivo. São Paulo: Aberje, 2005.

MARCONI, Marina de Andrade; LAKATOS, Eva Maria. Fundamentos da Metodologia Científica. 5 ed. São Paulo: Atlas, 2003.

METHODUS. Fala Gerente. Pesquisa exclusiva mostra que a comunicação nas empresas vai mal. São Paulo, 2013. Disponível em: <http://www.methodus.com.br/artigos_carreira/5/falagerente.html> Acesso em: 10 junho 2014.

NASSAR, Paulo; FIGUEIREDO, Rubens. O que é comunicação empresarial. São Paulo: Brasiliense, 1997.

PERSONA, Mário. Endomarketing e Comunicação Interna. 2010. Disponível em: <http://mariopersona.com.br/entrevista-endomarketing-comunicacao-rhmais.html> Acesso em: 12 Janeiro 2015.

PIMENTA, Maria Alzira. Comunicação empresarial. Campinas: Alínia, 2009.

REZIN, Graziela. A importância da comunicação empresarial interna para o sucesso de um empreendimento: estudo de caso aplicado em uma empresa de factoring. Criciúma, S.C., 2010. Disponível em:

<http://repositorio.unesc.net/bitstream/1/306/1/Graziela\%20Rezin.pdf> Acesso em: 13 junho 2014.

SILVA, Sandra S. F. da; NASCIMENTO, Taciana C.; NOGUEIRA, Viviane B.; Diagnóstico da Comunicação Interna e Desenvolvimento de um Plano Integrado de Comunicação Empresarial Pice no Hospital Regional de Picuí-PB. 2007. Disponível em:

<http://revista.uepb.edu.br/index.php/qualitas/article/view/95/76> Acesso em: 18 Janeiro 2015.

TORQUATO, Gaudêncio. Tratado de comunicação organizacional e política. 2. reimp. São Paulo: Cengage Learning, 2008.

TORQUATO, Gaudêncio. Cultura, poder, comunicação e imagem: fundamentos da nova empresa. 2. Reimp. São Paulo: Pioneira, 1998. 
TORQUATO, Gaudêncio. Comunicação empresarial / comunicação institucional: conceitos, estratégias, sistemas, estrutura, planejamento e técnicas. São Paulo: Summus, 1986. 